九州大学学術情報リポジトリ

Kyushu University Institutional Repository

Photosynthesis-Light Response Curve Derived from Light Absorbed in a Leaf : I. Model of Light Absorption in Each Mesophyll Layer of a Leaf

Hirota, Osamu

Laboratory of Crop Husbandry, Faculty of Agriculture, Kyushu University

https://doi.org/10.5109/23843

出版情報 : 九州大学大学院農学研究院紀要. 31 (3)，pp.191-201，1987-03-10. Kyushu University バージョン:

権利関係 : 


\title{
Photosynthesis-Light Response Curve Derived from Light Absorbed in a Leaf \\ I. Model of Light Absorption in Each Mesophyll Layer of a Leaf
}

\author{
Osamu Hirota \\ Laboratory of Crop Husbandry, Faculty of Agriculture, \\ Kyushu University 46-01, Fukuoka 812 \\ (Received July 30, 1986)
}

\begin{abstract}
Since a leaf has a certain thickness, each mesophyll layer in it absorbs different light energy. In this paper, by using parameters related with the light transmission and reflection of a leaf, the equation describing the absorption of light in each layer of a leaf was proposed. Spectral distribution of tobacco, soybean, corn and rice plant leaves with different chlorophyll content were measured by a spectra-photometer equipped with spherical ball and opal glass. Attenuation coefficients of visible light to chlorophyll content of a leaf on dicotyledonous plants (tobacco and soybean) were larger than that of monocotyledonous plants (corn and rice). But there was no difference of reflection coefficient in either plant type. On a leaf with high chlorophyll content, light absorption of lower mesophyll layer of a leaf was smaller than that on a leaf with low content.
\end{abstract}

\section{INTRODUCTION}

A fraction of the amount of light striking a leaf is reflected, and a fraction of it is absorbed, while the residual light passes through both sides of the leaf surface (Gates et al., 1965 ; Sinclair et al., 1971 ; Woolley et al., 1971). Chloroplasts near the lightedside of a leaf absorb more light energy than those on the opposite side, because of a certain thickness of a leaf. Photosynthetic rates of a leaf lighted from both sides on some plants (Moss, 1964 ; Tanaka and Matsushima, 1971a) are higher than those of a leaf lighted from one side only, because of the uniform light absorption in each layer within a leaf. Moss (1964) indicated that the investigation of the light-curve should take into consideration the thickness of a leaf. Yabuki and Ko (1973) indicated that the light-curve had different patterns, because the light transmission might depend on the leaf construction and incident light quality. Terashima and Saeki (1983) measured light intensity in each layer of a leaf of Camellia to estimate the effects of leaf thickness on leaf photosynthesis.

In this paper, I propose a model of light absorption in each mesophyll layer of a leaf, derived from the relationship of chlorophyll content of a leaf with its both light transmission and reflection. 


\section{MATERIALS AND METHODS}

Leaves with different chlorophyll contents of tobacco (var. Samsun), corn (var. Pionieer 3424), rice (var. Toyotama) and soybean (var. Tamanishiki) plants were used for investigating the relationship of chlorophyll content with reflection and transmission of a leaf for photosynthetically active radiation (PhAR).

The spectral transmittance and reflectance of a leaf were measured by using a spectra-photometer (Hitachi EPS-3T type) equipped with integrating spherical ball and opal glass, on the wavelength 400-700 nm (Hirota et al., 1974).

\section{RESULTS}

\section{Transmittance and reflectance}

Spectral distributions of transmittance $\tau_{\mathrm{L}, \lambda}$ and reflectance $\gamma_{\mathrm{L}}$, of tobacco leaves are shown in Fig. 1. The patterns of spectral distribution of other crops used were similar to tobacco leaves. On the high chlorophyll content of a leaf, light absorption is large, because of its little transmittance and reflectance. And there is a little absorption in a leaf with no chlorophyll.

The transmittance $T_{\mathrm{C}}$ and reflectance $R_{\mathrm{C}}$ at visible wavelength $(400-700 \mathrm{~nm})$ of the incident solar radiation are calculated by Eq. (1).

$T_{\mathrm{C}}=\Sigma\left(I_{\lambda} \bullet \tau_{1, \lambda}\right) / \Sigma I_{\lambda}$
$R_{\mathrm{C}}=\Sigma\left(I_{\lambda} \cdot r_{1, \lambda}\right) / \Sigma I_{\lambda}$

where $I_{A}$ is spectral light intensity of solar radiation at the wavelength $\lambda$ on the condition of air mass $=1$ (Robinson, 1966) and $\tau_{\mathrm{L}, \lambda}$ and $\gamma_{\mathrm{L}, \lambda}$ are spectral transmittance and reflectance at the wavelength $\lambda$, respectively.

The relationships of chlorophyll content $\mathrm{C}$ of a leaf with both reflectance $R_{\mathrm{C}}$ and

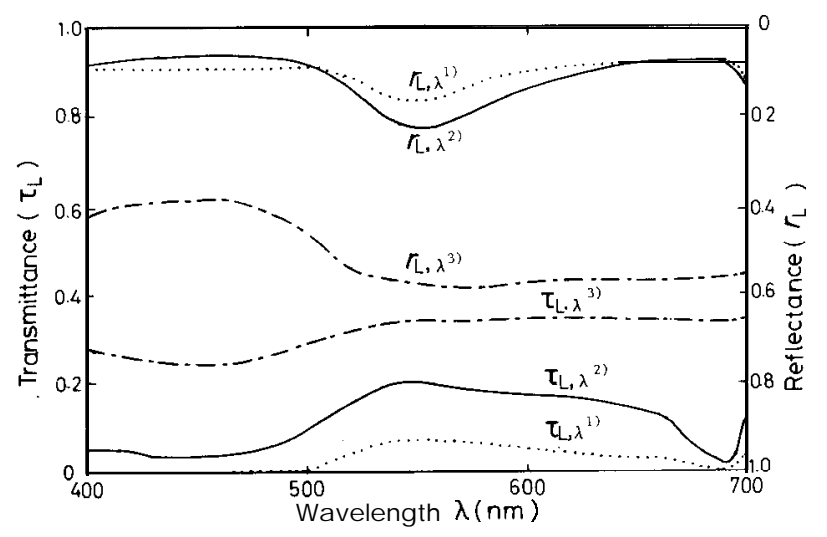

Fig. 1. Spectral transmittance $\tau_{L, \lambda}$ and reflectance $r_{L, \lambda}$ for PhAR of a tobacco leaf. Superscripts 1, 2 and 3 denote chlorophyll contents 4, 5, 1.43 and Omg chl/ $\mathrm{dm}^{2}$, respectively. 


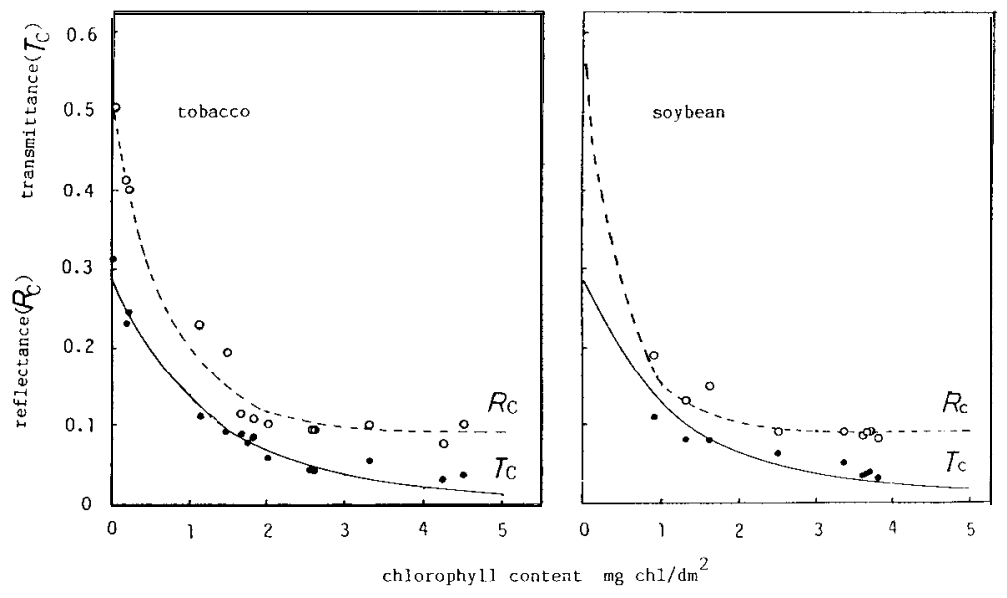

Fig. 2. Relationship of chlorophyll content within a leaf with its transmittance $T_{\mathrm{C}}$ and reflectance $R_{\mathrm{C}}$ for PhAR.

Table 1. Parameters used for characterizing the relationships of chlorophyll contents of a leaf with both transmittance $T_{\mathrm{C}}$ and reflectance $R_{\mathrm{C}}$ for PhAR of a leaf.

\begin{tabular}{lccccc}
\hline & \multicolumn{2}{c}{ transmittance } & \multicolumn{3}{c}{ reflectance } \\
& $T_{\mathrm{C} 0}$ & $\boldsymbol{K T C}$ & $T_{\mathrm{C} 0}$ & $K_{\mathrm{RC}}$ & $r_{\mathrm{s}}$ \\
\cline { 2 - 6 } & 0.281 & 0.684 & 0.418 & 1.395 & 0.09 \\
Tobacco & 0.285 & 0.776 & 0.468 & 1.979 & 0.09 \\
Soybean & 0.227 & 0.604 & 0.393 & 1.501 & 0.10 \\
Corn & 0.223 & 0.621 & 0.457 & 1.231 & 0.09 \\
Rice & & &
\end{tabular}

Notes; $T_{\mathrm{C} 0}$ and $R_{\mathrm{C} 0}$ are transmittance $T_{\mathrm{C}}$ and reflectance $R_{\mathrm{C}}$ of a leaf with no chlorophyll for $\mathrm{PhAR}$, respectively; $K_{\mathrm{TC}}$ and $K_{\mathrm{RC}}$ are attenuation coefficients for characterizing the relationship of chlorophyll contents within a leaf with both transmittance $T_{\mathrm{C}}$ and reflectance $R_{\mathrm{C}}$ for PhAR of a leaf, respectively; $r_{\mathrm{S}}$ is the critical reflectance for PhAR of a leaf.

transmittance $T_{\mathrm{C}}$ of tobacco, soybean, corn and rice plant leaves are shown in Fig. 2. Reflectance $R_{\mathrm{C}}$ is higher than transmittance $T_{\mathrm{C}}$ regardless of the chlorophyll content. Transmittance $T_{\mathrm{c}}$ decreased with increasing chlorophyll content C. Reflectance $R_{\mathrm{C}}$, also, decreased with increasing chlorophyll content $\mathrm{C}$ and converged to a $8 \sim 10 \%$ level on not so high chlorophyll content. These converging values of reflectance can be taken as the critical reflectance of a leaf surface. The relationships of the chlorophyll content $\mathrm{C}$ with both transmittance $T_{\mathrm{C}}$ and reflectance $R_{\mathrm{C}}$ is approximated to the exponential function (Fig. 2). Reflectance $R_{\mathrm{C}}$ consists of both the critical reflection of a leaf surface and the reflection due to the mesophyll tissue within a leaf. The relationships of chlorophyll contents $\mathrm{C}$ within a leaf with both transmittance $T_{\mathrm{C}}$ and reflectance $R_{\mathrm{C}}$ are shown by Eqs. (2) and (3), respectively.

$$
\begin{aligned}
& T_{\mathrm{C}}=T_{\mathrm{C} 0} \exp \left(-K_{\mathrm{TC}} C\right) \\
& R_{\mathrm{C}}=R_{\mathrm{C} 0} \exp \left(-K_{\mathrm{RC}} C\right)+r_{\mathrm{S}}
\end{aligned}
$$

where $T_{\mathrm{C} 0}$ and $R_{\mathrm{C} 0}$ are transmittance and reflectance of a leaf with no chlorophyll, 
respectively ; $K_{\mathrm{TC}}$ and $K_{\mathrm{RC}}$, constants showing the relationships of chlorophyll contents with transmittance and reflectance, respectively ; $\mathrm{C}$, chlorophyll content of a leaf $; r_{\mathrm{S}}$ critical reflection of a leaf surface.

The $T_{\mathrm{C} 0}$ and $K_{\mathrm{TC}}$ in Eq. 2 were determined statistically by the method of least squares using the linear relationship between chlorophyll contents $\mathrm{C}$ and $\ln$ of transmittance $T_{\mathrm{C}}$ in Fig. 2. The $R_{\mathrm{C} 0}, K_{\mathrm{RC}}$ and $\gamma_{\mathrm{S}}$ in eq. (3) were determined by the following procedure. First of all, we regard the converged value of reflectance $R_{\mathrm{C}}$ in Fig. 2 as a critical reflectance $\gamma_{\mathrm{S}}$. Then, $R_{\mathrm{C} 0}$ and $K_{\mathrm{RC}}$ were determined by using the linear relationship between chlorophyll contents $\mathrm{C}$ of a leaf and $\ln \left(R_{\mathrm{C}}-\gamma_{\mathrm{S}}\right)$. The parameters obtained are shown in Table. 1.

Parameters both $T_{\mathrm{C} 0}$ and $K_{\mathrm{TC}}$ which consist of transmittance $T_{\mathrm{C}}$ of dicotyledonous plant leaves (tobacco and soybean) are higher than those of monocotyledonous plant (corn and rice). But there is no difference in reflectance $R_{\mathrm{C}}$ among plant species used. Sinclair et al. (1971) also, reported no difference in reflectance for the visible wavelength between monocotyledonous and dicotyledonous plants.

\section{Model of light absorption in each mesophyll layer of a leaf.}

In order to make equations which describe the light flux in a leaf using the parameters in Table 1, an assumption has been made that a leaf has a certain thickness $M_{\mathrm{L}}$ and the chlorophyll is distributed in a leaf uniformly. Therefore, as shown in Fig. 3, it can be assumed that incident light on upper surface of a leaf, excepting the critical reflection $r_{\mathrm{S}}$, attenuates in a leaf according to Beer's law. If we assume the incident light as unit, light flux at a layer A4 measured from upper surface of a leaf is shown by Eq. (4).

$$
T_{\mathrm{M}}=\left(1-r_{\mathrm{S}}\right) \exp \left(-K_{\mathrm{TM}} M\right)
$$

where $K_{\mathrm{TM}}$ is the extinction coefficient of light intensity in a leaf. Downward flux $T_{\mathrm{ML}}$ at the bottom layer of a leaf is

$$
T_{\mathrm{ML}}=\left(1-r_{\mathrm{S}}\right) \exp \left(-K_{\mathrm{TM}} M_{\mathrm{L}}\right)
$$

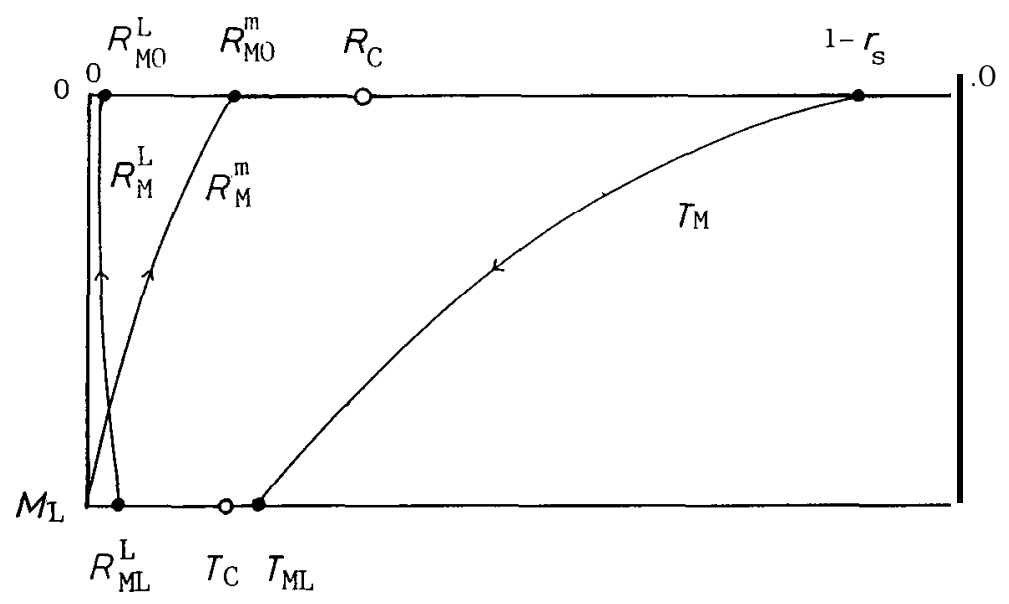

Fig. 3. Schematic illustration for evaluating PhAR absorbed by each layer of a leaf. Symbols as in text. 
where $M_{\mathrm{L}}$ is the leaf thickness. The $T_{\mathrm{ML}}$ consists of both flux due to the critical reflection $\mathrm{R} \underset{\mathrm{ML}}{\stackrel{\mathrm{L}}{L}}$ of light traveling from the leaf into the air and flux due to transmission $T_{\mathrm{c}}$.

$$
T_{\mathrm{ML}}=R_{\mathrm{ML}}^{\mathrm{L}}+T_{\mathrm{C}} .
$$

The $R_{\mathrm{ML}}^{L}$ is shown by Eq. (7)

$$
R_{\mathrm{ML}}^{\mathrm{L}}=\gamma_{\mathrm{SL}} T_{\mathrm{ML}} \text {, }
$$

where $\gamma_{\mathrm{SL}}$ is the critical reflection of light traveling from a leaf into the air. The $\gamma_{\mathrm{SL}}$ can be determined by using the general relationship (Wood, 1936) between critical reflection $r_{\mathrm{S}}$ and refractive index $n_{\mathrm{AL}}$ of light traveling from the air into a leaf, which is

$$
r_{\mathrm{S}}=\frac{\left(1-n_{\mathrm{AL}}\right)^{2}}{\left(1+n_{\mathrm{AL}}\right)^{2}}
$$

Substituting $r_{\mathrm{S}}$ obtained in Fig. 2 to Eq. (8), $n_{\mathrm{AL}}$ can be calculated. Using $n_{\mathrm{AL}}$, the refractive index $n_{\mathrm{LA}}$ of light traveling from the leaf into the air can be calculated by Es. (9).

$$
\mathrm{n}_{\mathrm{LA}}=\frac{1}{n_{\mathrm{AL}}} \text {. }
$$

Critical reflection $\gamma_{\mathrm{SL}}$ of light traveling from a leaf into the air is

$$
r_{\mathrm{SL}}=\frac{\left(n_{\mathrm{LA}}-1\right)^{2}}{\left(n_{\mathrm{LA}}+1\right)^{2}} \text {. }
$$

Then, substituting Eq. (9) into Eq. (10),

$$
r_{\mathrm{SL}}=\frac{\left(1-n_{\mathrm{AL}}\right)^{2}}{\left(1+n_{\mathrm{AL}}\right)^{2}} .
$$

The $r_{\mathrm{SL}}$ in Eq. (11) is the same as $r_{\mathrm{S}}$ in Eq. (8).

The upward flux due to the critical reflection $r_{S_{L}}$ attenuates because of being absorbed by leaf tissues. This extinction coefficient can be assumed to be the same as that of the downward flux $K_{T M}$, because all of the light into a leaf is scattered. Then, upward flux at the layer $\mathrm{M}$ in a leaf is,

$$
R_{\mathrm{M}}^{\mathrm{L}}=R_{\mathrm{ML}}^{\mathrm{L}} \exp K_{\mathrm{TM}}(M-M,\lrcorner \text {. }
$$

On the other hand, in Fig. 3, the upward flux $\left(R_{\mathrm{C}}-r_{\mathrm{S}}\right)$ [except the critical reflection $r_{\mathrm{S}}$ at the upper surface of a leaf] consists of $R_{\mathrm{M} 0}^{\mathrm{m}}$, due to the leaf tissue, and $R_{\mathrm{M} 0}^{\mathrm{L}}$, due to the critical reflection of light traveling from a leaf into the air [Eq. (13)].

$R_{\mathrm{C}}-r_{\mathrm{S}}=R_{\mathrm{M} 0}^{\mathrm{m}}+R_{\mathrm{M} 0}^{\mathrm{L}}$.

Substituting $R_{\mathrm{M} 0}^{\mathrm{L}}$ obtained from Eq. (12) (in which $\mathrm{M}=0$ ) to Eq. (13), we can obtain upward flux $R_{\mathrm{M} 0}^{\mathrm{m}}$, which is reflected by mesophyll tissues, at the upper surface of a leaf, $R_{\mathrm{M} 0}^{\mathrm{m}}=\left(R_{\mathrm{C}}-r_{\mathrm{S}}\right)-R_{\mathrm{ML}}^{\mathrm{L}} \exp \left(-K_{\mathrm{TM}} M_{\mathrm{L}}\right)$.

Supposing a thin layer $\mathrm{d} M$ at layer $\mathrm{M}$ measured from the upper surface of a leaf, we can express upward flux, reflected by $\mathrm{d} M$, by $\mathrm{d} R_{\mathrm{M}}^{\mathrm{m}}$. Since $\mathrm{d} R_{\mathrm{M}}^{\mathrm{m}}$ is proportional to the downward flux $T_{\mathrm{M}}$ at the layer $\mathrm{M}$ in a leaf, we can obtain Eq. (15) by using a proportional constant a,

$$
\frac{\mathrm{d} R_{\mathrm{M}}^{\mathrm{m}}}{\mathrm{d} M}=a T_{\mathrm{M}}
$$


$=a(1-\mathrm{r},) \exp \left(-K_{\mathrm{TM}} M\right)$.

Integrating Eq. (15) with respect to $M$ from $M=0$ to $M=M_{\mathrm{L}}$, we can get the upward flux $R_{\mathrm{M} 0}^{\mathrm{m}}$, which is reflected by mesophyll tissues, at the upper surface of a leaf [Eq. (16)],

$$
\begin{aligned}
R_{\mathrm{M} 0}^{\mathrm{m}} & =\int_{0}^{M_{m}} \frac{\mathrm{d} R_{\mathrm{M}}^{\mathrm{m}}}{\mathrm{d} M} \mathrm{~d} M \\
& =a \frac{\left(1-r_{\mathrm{S}}\right)}{K_{\mathrm{TM}}}\left[1-\exp \left(-K_{\mathrm{TM}} M_{\mathrm{L}}\right)\right]
\end{aligned}
$$

Therefore, proportional constant a in Eq. (15) is obtained from Eqs. (14) and (16), $a=\frac{K_{\mathrm{TM}}\left(R_{\mathrm{C}}-r_{\mathrm{S}}-R_{\mathrm{ML}}^{\mathrm{L}} \exp \left(-K_{\mathrm{TM}} M_{\mathrm{L}}\right)\right.}{\left(1-r_{\mathrm{S}}\right)\left(1-\exp \left(-K_{\mathrm{TM}} M_{\mathrm{L}}\right)\right)}$.

Upward flux $R_{\mathrm{M}}^{\mathrm{m}}$ at the layer $\boldsymbol{M}$ in a leaf is equal to the upward flux which is the integrated light being reflected by mesophyll tissues beneath the layer $M$. Therefore, $R_{\mathrm{M}}^{\mathrm{m}}$ is obtained by integrating Eq. (15) with respect to $\boldsymbol{M}$ from $\boldsymbol{M}=\boldsymbol{M}$ to $\boldsymbol{M}=M_{\mathrm{L}}$ [Eq. (18)].

$$
R_{\mathrm{M}}^{\mathrm{m}}=\frac{\left\{R_{\mathrm{C}}-r_{\mathrm{S}}-R_{\mathrm{ML}}^{\mathrm{L}} \exp \left(-K_{\mathrm{TM}} M_{\mathrm{L}}\right)\right\rceil\left[\exp \left(-K_{\mathrm{TM}} M\right)-\exp \left(-K_{\mathrm{TM}} M_{\mathrm{L}}\right)\right]}{1-\exp \left(-K_{\mathrm{TM}} M_{\mathrm{L}}\right)}
$$

The extinction coefficient $K_{\text {TM }}$ of downward flux in a leaf is calculated from Eq. (19), which is obtained from Eqs. (2), (5) and (10).

$$
K_{\mathrm{TM}}=-\frac{\ln \left[T_{\mathrm{CO}} /\left(1-r_{\mathrm{S}}\right)^{2}\right]-K_{\mathrm{TC}} C}{M_{\mathrm{I}}}
$$

Next, we must determine the light absorption of each layer in a leaf as following.

First of all, considering the direction of light traveling in a leaf, we determine the direction from the upper surface of a leaf to downward as positive and upward as negative. Therefore, upward flux $R_{\mathrm{M}}^{\mathrm{L}}$ [Eq. (12)] and $R_{\mathrm{M}}^{\mathrm{m}}$ [Eq. (IS)] are negative. If we determine the light absorption of a leaf as positive, the light absorption $\alpha M$ at the layer $\boldsymbol{M}$ is,

$$
\alpha M=-\frac{\mathrm{d} T_{\mathrm{M}}}{\mathrm{d} M}-\left(-\frac{\mathrm{d} R_{\mathrm{M}}^{\mathrm{L}}}{\mathrm{d} M}-\left(-\frac{\mathrm{d} R_{\mathrm{M}}^{\mathrm{m}}}{\mathrm{d} M}\right)\right.
$$

The $\alpha M$ is calculated from Eq. (21) which is obtained by substituting the differentiated Eqs. (4), (12) and (18) with respect to $\boldsymbol{M}$ into Eq. (20),

$$
\begin{aligned}
\alpha M= & K_{\mathrm{TM}}\left\{\left(1-r_{\mathrm{S}}\right) \exp \left(-K_{\mathrm{TM}} M\right)+R_{\mathrm{ML}}^{\mathrm{L}} \exp K_{\mathrm{TM}}\left(M-M_{\mathrm{L}}\right)\right. \\
& \left.-\frac{\left[R_{\mathrm{C}}-r_{\mathrm{S}}-R_{\mathrm{ML}}^{\mathrm{L}} \exp \left(-K_{\mathrm{TM}} M_{\mathrm{L}}\right)\right] \exp \left(-K_{\mathrm{TM}} M\right)}{1-\exp \left(-K_{\mathrm{TM}} M_{\mathrm{L}}\right)}\right\}
\end{aligned}
$$

The light absorption $\boldsymbol{A}$ of the whole layer of a leaf is obtained by integrating Eq. (21) with respect to $M$ from $M=0$ to $M=M_{\mathrm{L}}$,

$$
\begin{aligned}
A & =\int_{0}^{M_{L}} \alpha M \mathrm{~d} M \\
& =1-R_{\mathrm{C}}-\left(1-r_{\mathrm{S}}\right) \exp \left(-K_{\mathrm{TM}} M_{\mathrm{L}}\right)+R_{\mathrm{ML}}^{\mathrm{L}} .
\end{aligned}
$$

The light absorption $A$, from the surface to a layer $\boldsymbol{M}$ in a leaf is, 


$$
\begin{aligned}
A_{\mathrm{M}}= & \int_{0}^{M} \alpha M \mathrm{~d} M \\
= & \left(1-r_{\mathrm{S}}\right)\left[1-\exp \left(-K_{\mathrm{TM}} M\right)\right]+R_{\mathrm{ML}}^{\mathrm{L}}\left[\exp K_{\mathrm{TM}}\left(M-M_{\mathrm{L}}\right)-\exp \left(-K_{\mathrm{TM}} M_{\mathrm{L}}\right)\right] \\
& -\frac{\left[R_{\mathrm{C}}-r_{\mathrm{S}}-R_{\mathrm{ML}}^{\mathrm{L}} \exp \left(-K_{\mathrm{TM}} M_{\mathrm{L}}\right)\right]\left[1-\exp \left(-K_{\mathrm{TM}} M\right)\right]}{1-\exp \left(-K_{\mathrm{TM}} M_{\mathrm{L}}\right)}
\end{aligned}
$$

Also, light absorption $A_{\mathrm{L}}$ from the layer $\mathrm{M}$ to $\mathrm{M}_{\mathrm{L}}$ is,

$$
\begin{aligned}
A_{\mathrm{L}}= & \int_{M}^{M_{L}} \alpha M \mathrm{~d} M \\
= & \left(1-r_{\mathrm{S}}\right)\left[\exp \left(-K_{\mathrm{TM}} M\right)-\exp \left(-K_{\mathrm{TM}} M_{\mathrm{L}}\right)\right]+R_{\mathrm{ML}}^{\mathrm{L}}\left[1-\exp K_{\mathrm{TM}}\left(M-M_{\mathrm{L}}\right)\right] \\
& +\left[R_{\mathrm{C}}-r_{\mathrm{s}}-R_{\mathrm{ML}}^{\mathrm{L}} \exp \left(-K_{\mathrm{TM}} M_{\mathrm{L}}\right)\right] \frac{\exp \left(-K_{\mathrm{TM}} M_{\mathrm{L}}\right)-\exp \left(-K_{\mathrm{TM}} M\right)}{1-\exp \left(-K_{\mathrm{TM}} M_{\mathrm{L}}\right)}
\end{aligned}
$$

\section{DISCUSSION}

Using parameters in Table 1 and assuming a leaf thickness $M_{\mathrm{L}}=1$, the extinction coefficients $K_{\mathrm{TM}}$ of light in a leaf with different chlorophyll contents were calculated from Eq. (19) (Table 2).

Profiles of light flux in a tobacco leaf obtained from Eq. (4) by using the attenuation coefficient $K_{\mathrm{TM}}$ in Table 2 are shown in Fig. 4. Figure 4 also shows the downward flux of light in a leaf obtained from Eq. (4), because we assumed the incident light intensity on a leaf as unit. Downward flux attenuate rapidly in a leaf with higher chlorophyll content.

Figure 5 shows both upward flux of $R_{\mathrm{M}}^{\mathrm{m}}$ due to the reflection of mesophyll tissue and that of $R_{\mathrm{M}}^{\mathrm{L}}$ due to the critical reflection of light traveling from the leaf to the air. The $R_{\mathrm{M}}^{\mathrm{m}}$ and $R_{\mathrm{M}}^{\mathrm{L}}$ were calculated from Eqs. (18) and (12), respectively. The $R_{\mathrm{M}}^{\mathrm{m}}$ increased upward and $R_{\mathrm{M}}^{\mathrm{L}}$ decreased upward. Both $R_{\mathrm{M}}^{\mathrm{m}}$ and $R_{\mathrm{M}}^{\mathrm{L}}$ of upward flux decreased upward in a leaf with higher chlorophyll content.

The light absorption rate $\alpha M$ in each layer of a leaf is shown in Fig. 6. Even

Table 2. Relationship between exinctino coefficicextinction $r \mathrm{PhAR}$ in a leaf and its chlorophyll content of several crops.

\begin{tabular}{lcccccc}
\hline & \multicolumn{7}{c}{ chl mg/dm } \\
& 0 & 1 & 2 & 3 & 4 & 5 \\
\cline { 2 - 6 } & & \multicolumn{7}{c}{$K_{\text {TM }}$} \\
Tobacco & 1.08 & 1.76 & 2.45 & 3.13 & 3.82 & 4.50 \\
Soybean & 1.07 & 1.84 & 2.62 & 3.39 & 4.17 & 4.95 \\
Corn & 1.27 & 1.88 & 2.48 & 3.08 & 3.69 & 4.29 \\
Rice & 1.27 & 1.89 & 2.51 & 3.13 & 3.75 & 4.37 \\
\hline
\end{tabular}




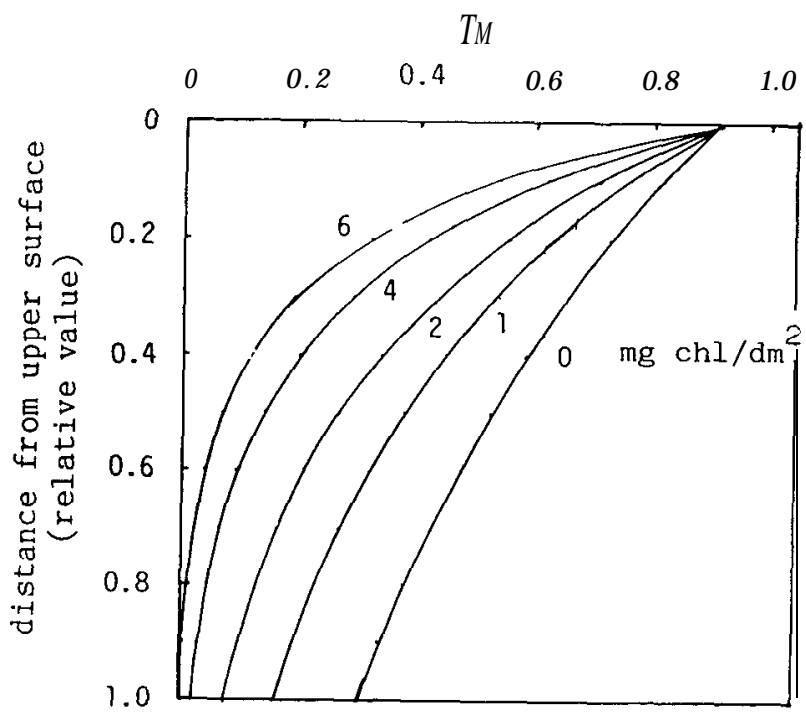

Fig. 4. Downward flux $T_{\mathrm{M}}$ of PhAR in a tobacco leaf.

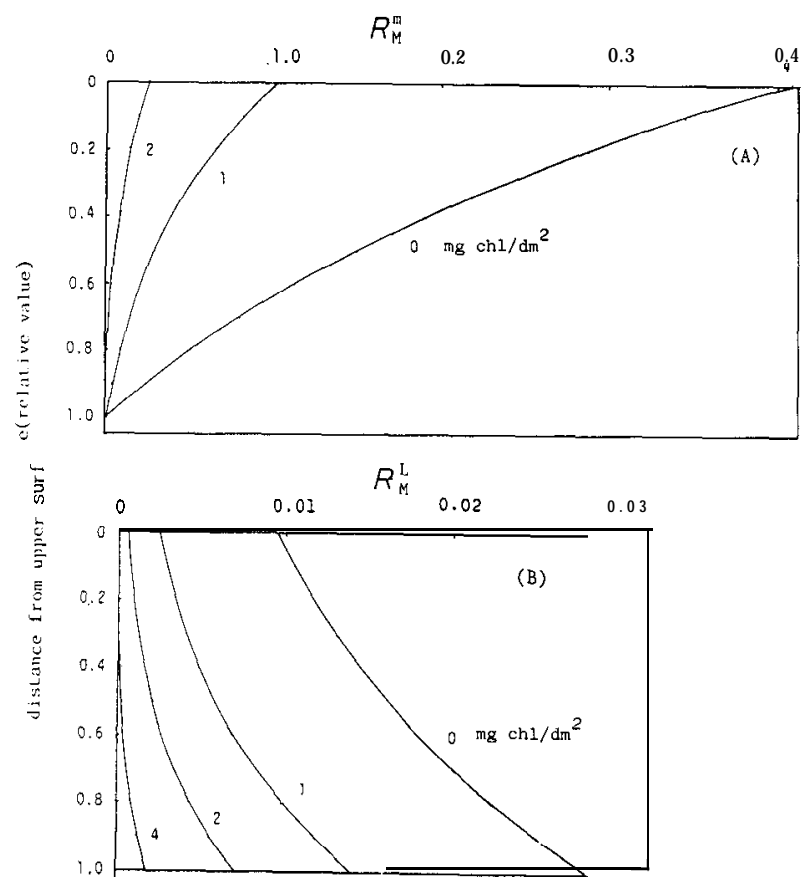

Fig. 5. Upward flux of PhAR in a tobacco leaf.

(A) shows the upward flux $R_{\mathrm{M}}^{\mathrm{m}}$ due to a leaf tissue. (B) shows the upward flux $R_{\mathrm{M}}^{\mathrm{L}}$ due to the critical reflection of light traveling from a leaf into the air. 


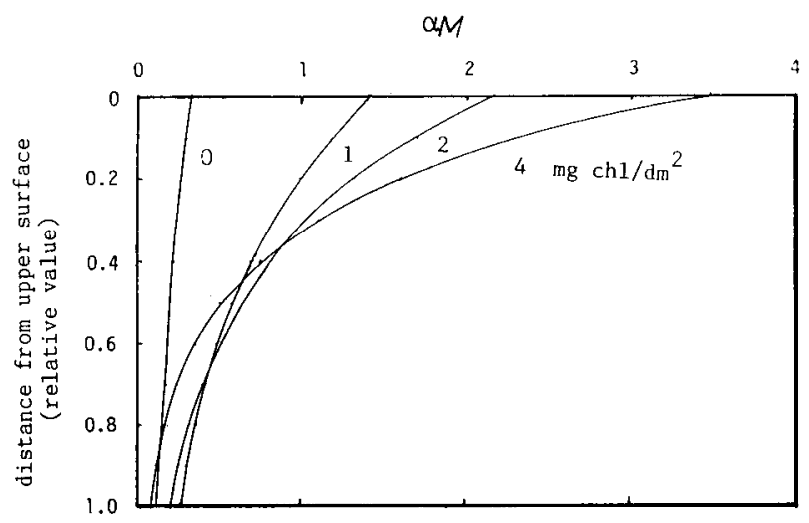

Fig. 6. Absorptivity $\alpha M$ for PhAR in each layer within a tobacco leaf.

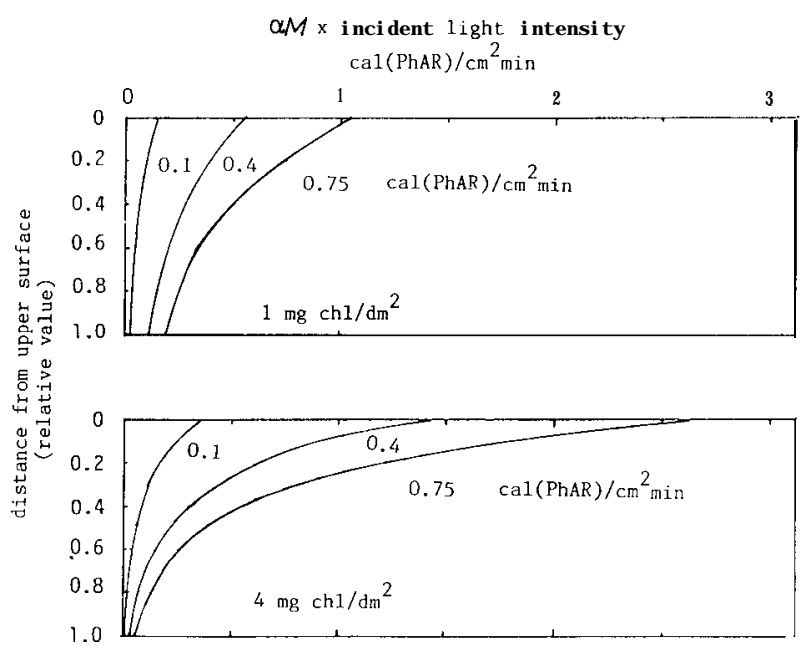

Fig. 7. PhAR absorbed by each layer of a tobacco leaf at various incident lights.

though a leaf chlorophyll content is low, each mesophyll layer absorbs light energy almost uniformly from its upper surface to the bottom. On a leaf with a higher chlorophyll content, most of the incident light is absorbed by the upper layers. On a leaf with a low chlorophyll content, however, more light is absorbed by the lower layers.

The light absorbed by each layer of tobacco leaves with chlorophyll content 1 and $4 \mathrm{mg} / \mathrm{dm}^{2}$ are shown in Fig. 7. The upper layers of a leaf with high chlorophyll content absorb more light than lower layers. This suggests a reason for the phenomenon reported by Tanaka and Matsushima (1971b) (that abaxial surface photosynthesis of a leaf with high chlorophyll content was lower than that of a leaf with low content).

The relationships between the chlorophyll content and light absorption rate of a 


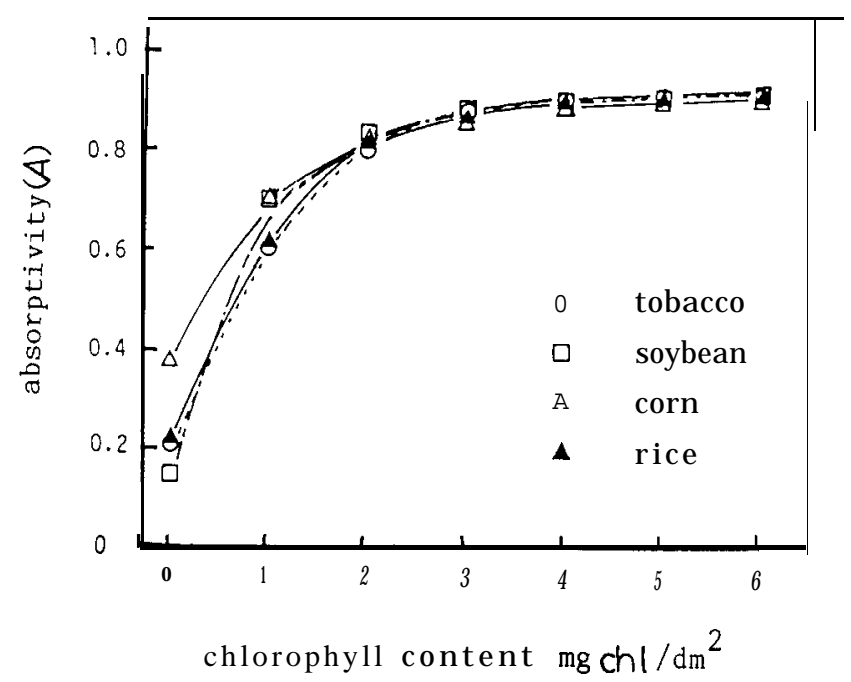

Fig. 8. Relationship between absorptivity $A$ for PhAR of the whole layer of a leaf and its chlorophyll content.

leaf the 4 crop species used are shown in Fig. 8, which has been calculated from Eq. (22). The light absorption rate $A$ is different among crops with a lower chlorophyll content of a leaf. It might become because of the differences in the architecture within the leaves used. This difference of light absorption rate among crops disappears beyond $4 \mathrm{mg} \mathrm{chl} / \mathrm{dm}^{2}$.

\section{ACKNOWLEDGEMENT}

The author wishes to thank Dr. M. Yoshida for his helpful discussion.

\section{REFERENCES}

Gates, D. M., H. J. Keegan, J. C. Schleter and V. R. Weidner 1965 Spectral properties of plants. Appl, Opt., 4: 11-17

Hirota, O., T.Akiyama, T. Takeda, T. Matsui and I. Aiga 1974 Studies on the role of light transmissibility of single leaf and plant type as factors constituing light extinction coefficient $K$ in corn plant populations. Proc.Crop Sci. Soc.Jpn., 43: 283-288 (in Japanese with English summary)

Moss, D. N. 1964 Optimum lighting leaves. Crop Sci., 4:131-136

Robinson, N. 1966 The energy distribution in the spectrum of direct and scattered radiation reaching the earth. In "Solar radiation", ed. by N. Robinson, Elesvier Publ. Comp., New York, p. 162

Sinclair, T. R., M. M. Scriber and R. M. Hoffer 1973 Diffuse reflectance hypothesis for the pathway of solar radiation through leaves. Agron. Jour., 65:268-283

Tanaka, T. and S. Matsushima 1971a Analysis of yield-determining process and its application and culture improvement of lowland rice. XCIV. Relation between the light intensity on both sides 
and the amount of carbon assimilation in each side of a single leaf-blade. Proc. Crop Sci. Soc. Jpn., 39 : 325-329 (in Japanese with English summary)

Tanaka, T., and S. Mastushima 1971b Analysis of yield-determining process and its application and culture improvement of lowland rice. XCVIII. Effects of nitrogen content and thickness of a leaf-blade on the light-curve of carbon assimilation of the obverse, the reverse and both sides of the leaf-blade. Proc. Crop Sci. Soc. Jpn., 40 : 1644169 (in Japanese with English summary)

Terashima, I. and T. Saeki 1983 Light environment within a leaf I. Optical properties of paradermal sections of Camellia leaves with special reference to differences in the optical properties of palisade and spongy tissues. Plant and Cell Physiol., 24 :1493-1501

Wood, R. W. 1936 Physical optics (Third edition), The Macmillan Company, New York, p. 411

Woolley, J. T. 1971 Reflectance and transmittance of light by leaves. Plant Physiol., 47 : 656-662

Yabuki, K. and B. Ko 1973 The dependence of photosynthesis in several vegetables on light quality. Agr. Meteor., $29:$ 17-23 (in Japanese with English summary) 